\title{
Expert system for heart disease based on electrocardiogram data using certainty factor with multiple rule
}

\author{
Sumiati $^{1}$, Hoga Saragih ${ }^{2}$, Titik Khawa Abdul Rahman ${ }^{3}$, Agung Triayudi ${ }^{4}$ \\ ${ }^{1}$ Information and Communication Technology, Universitas Serang Raya, Indonesia \\ ${ }^{2}$ Information and Communication Technology, Universitas Bakrie, Indonesia \\ ${ }^{1,3}$ Department of School and Graduate, Asia e University, Malasyia \\ ${ }^{4}$ Informatic Department, Universitas Nasional, Indonesia
}

\begin{tabular}{l}
\hline \hline Article Info \\
\hline Article history: \\
Received Apr 17, 2020 \\
Revised Dec 23, 2020 \\
Accepted Jan 2, 2021
\end{tabular}

Keywords:

Accuracy

Certainty factor

Expert systems

Heart disease

Multiple rule

\begin{abstract}
Limited public health services in remote areas, where the lack of transportation infrastructure, facilities, communication facilities and minimal medical personnel, especially for areas with underdeveloped, foremost, and regular (3T) status. The limitation of medical personnel is one of the factors for the high mortality rate of heart disease. On the other hand, the development of information technology, especially in the field of computing, is very fast in the era of the industrial revolution 4.0, but not yet used optimally, especially in the health sector. This study aims to develop a system or software that can replace a doctor for the process of identifying heart defects based on an expert system. Expert system developed with the certainty factor with multiple rule approach. System testing is carried out from the results of the system validity with experts, so that the system test results produce a certainty factor value for a normal heart of 0.95 and an accuracy level of $95 \%$, while the certainty factor $(\mathrm{CF})$ value for an abnormal heart is 0.99 and produces an accuracy rate of $99 \%$.
\end{abstract}

This is an open access article under the CC BY-SA license.

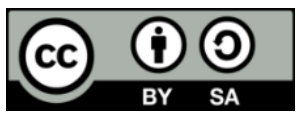

Corresponding Author:

Sumiati

Department of School and Graduate

Asia e University

Wisma Subang Jaya, No.106, Jalan ss15/4 Subang Jaya, 47500 Selangor, Malaysia

Email: sumiatihartoyo52@gmail.com

\section{INTRODUCTION}

The development of information technology at the time of the industrial revolution 4.0 was growing rapidly, which can be seen from various sciences, especially data mining, expert systems, fuzzy logic and others [1]. Apart from the field of education in the online learning process, besides that, the health sector can also be used for the diagnosis of a disease using a system that can replace an expert known as an expert system [2-4]. The problem in this study lies in the limitations of community health services in remote areas, where is the lack of transportation infrastructure, facilities, means of communication and minimal medical personnel, especially for areas with underdeveloped, frontier and regular (3T) status. Factors of limited medical personnel, is one of the factors causing the high number of patients to die from heart disease. On the other hand, the development of information technology, especially in the field of computing, is growing very rapidly, but not used optimally, especially in the health sector. In addition, the problems that exist with the EKG device are not currently able to analyze and identify the patient's heart, ECG tools only display graphs, not displaying the final results of heart abnormalities, so it still requires a cardiologist to be able to present the results of the ECG medical record [5]. So that with existing problems it is very necessary to make a 
system that can replace the position of an expert, where this system is able to adopt the expertise of an expert into a system, with the expert system is able to overcome the problem of shortages of specialists in the health sector, especially heart disease. The system built for the identification of heart defects is known as an expert system with a certainty factor approach with multiple rules, the certainty factor method is a simple computational model that allows experts to estimate confidence in conclusions.

An expert system that is built requires a basic knowledge process, where the basic knowledge of an expert can be adopted into an application [6-7]. The knowledge acquisition process is an extraction process, who is able to gather expert knowledge from one or more sources, so that the results of data extraction can affect the output of a system. Expert system is a breakthrough in the development of information technology which was developed with the aim of adopting the ability of an expert to diagnose a disease [8-10]. Expert system can help a patient and a layman to be able to communicate about a disease without being limited by distance and geographical conditions of the country [11-12]. The user will be assisted or followed by instructions from the system to convey in detail and in stages.

In general, the application of expert systems is widely used in the health sector for the diagnosis of a disease, such as the use of multiple rule certainty factors for the diagnosis of internal disease [13-14], ECG diagnosis using the supervised learning algorithms approach [15-17], heart diagnosis with a data mining method approach [18-21], diagnosis of heart disease with the approach of statistical analysts [22], diagnosis of heart disease using a decision tree approach [23], diagnosis of heart disease using the Pearson correlation coefficient method [24], identify cardiac abnormalities based on expert systems and telemedicine [25-28], single lead ECG classification with deep learning method approach [29-31], Detecting heart rate with machine learning approach [32-36], software for ECG classification analysis based on fuzzy cognitive map [37-38], improve the diagnosis of heart disease with the PSO evolutionary algorithm approach and neural network [39], ECG classification uses the k-nearest neigbor (KNN) approach [40]. This research has the aim and motivation to develop a system or software that can replace a doctor for the process of identifying heart defects based on an expert system with the certainty factor with multiple rule method approach, so that this software is able to identify heart defects, and can contribute in the health sector in particular, so that this expert system provides convenience in the consultation process between doctors (experts) and patients. With the expert system will provide a solution to every complaint of complaints felt by patients, so that the expert system is able to provide solutions to problems containing uncertainty as from the symptoms of a disease with other diseases.

\section{METHOD}

Expert systems

Expert systems is a branch of science that adopts one's expertise into an application, where the information provided by an expert regarding knowledge can be used for the consultation process. With the existence of expert systems can help ordinary people to solve existing problems, so that with the expert systems can make decisions that are usually made by an expert, but still consult an expert [41].

\section{Heart disease}

Heart disease is a condition when the main blood vessels are damaged while supplying blood to the heart (coronary arteries). Heart attack is an implication of heart disease, while cardiovascular it self is a blood vessel that supplies blood to the heart. Heart conditions can be determined through a heart test through an electrocardiagram (EKG) to determine normal and abnormal heart conditions [42], the following is an explanation of normal and abnormal heart.

\section{Normal heart}

A person's health condition to see the health condition of the heart, by doing a physical examination of the heart, a physical examination of the heart, a CT scan of the heart, and echocardiography. Echocardiography process to determine and see blood flow, whereas with the CT scan process of the heart to find out the anatomical condition of the heart, while normal heart sounds can be heard during the stethoscope examination process, heart sounds can be used as a measure to determine a person's heart health condition [43]. The general picture of the normal signal pattern of the human heart is shown in Figure 1. 


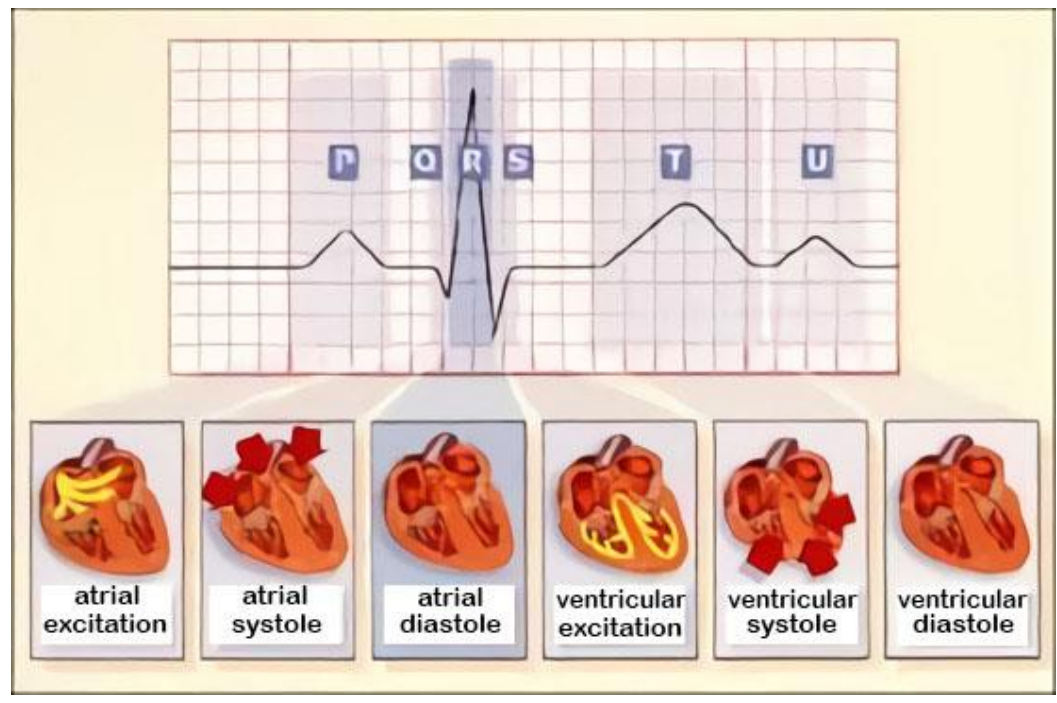

Figure 1. Normal heart pattern

Abnormal heart

An overview of the abnormal signal pattern of the human heart. Aortic regurgitation is regurgitation of the aortic valve is the return of blood to the left ventricle from the aorta during diastole. Abnormal heartbeat the rhythm can sound irregular, and sometimes there is an additional heartbeat sound or noise outside of the main heartbeat sound, the pattern is as shown in Figure 2.

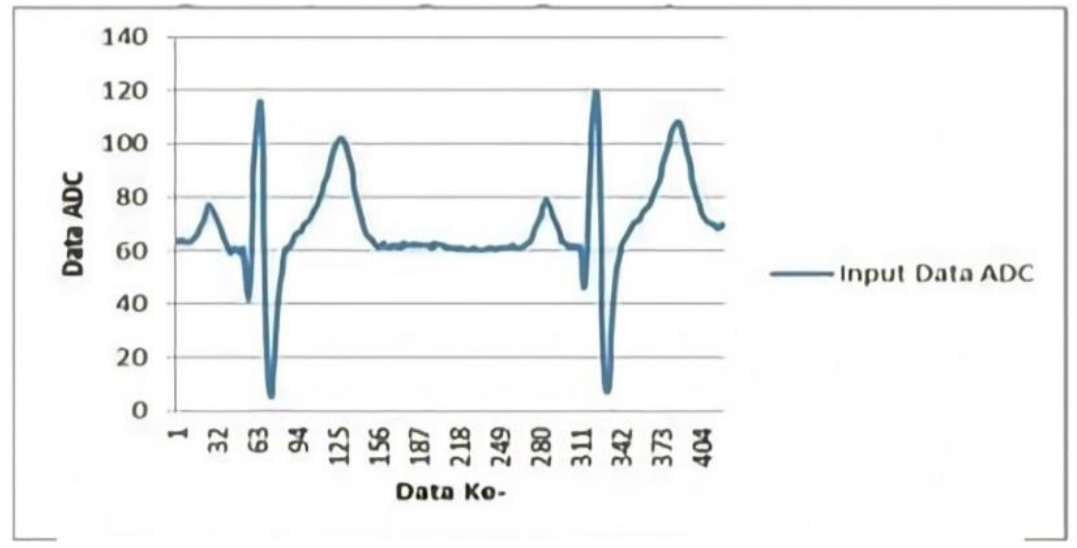

Figure 2. Aortic regurtitation cardiac ECG rhythm pattern

Certainty Factor

The certainty factor (CF) method is a measure of certainty against evidence or rules. The CF method has the advantage of measuring definite or uncertainty in the disease diagnosis process. The application of the $\mathrm{CF}$ method to an expert system requires several rules in the form of variables and weight values given by the expert. The notation certainty factors are explained:

$$
C F[h, e]=M B[h, e]-M D[h, e]
$$

The confidence propagation for a rule with one premise is obtained by the formula:

$$
C F(\text { Hypothesis, Evidence })=C F(\text { Evidence }) * C F(R U L E)
$$

There are two kinds of liaison with several premises, namely rules with conjunctions and rules with disjunctions, the approaches used are: 


$$
C F(H, \text { Evidence } 1 \text { AND Evidence } 2 A N D \ldots)=\min \{C F(E i)\} * C F(R U L E)
$$

Rule with disjunction, the approach used is:

$$
\text { CF (Hypothesis, Evidence } 1 \text { OR Evidence } 2 \text { OR } \ldots)=\max \{C F(E i)\} * C F(R U L E)
$$

Rule with the same conclusion, therefore there must be a mechanism to combine these several hypotheses to become one hypothesis only, as shown in (5.a-5c).

$$
\begin{aligned}
& C F C(C F 1, C F 2)=C F 1+C F 2(1-C F 1) ; \text { if } C F 1 \text { and } C F 2 \text { are both positive } \\
& C F C(C F 1, C F 2)=C F 1+C F 2(1+C F 1) ; \text { if } C F 1 \text { and } C F 2 \text { are both negative } \\
& C F C(C F 1, C F 2)=C F 1+C F 2(1+C F 1) ; \text { if } C F 1 \text { and } C F 2 \text { are both negative }
\end{aligned}
$$

In this study, we carried out the process of combining several hypotheses, while for a single premise, we used a conjunction approach, the value of CF entered between 0 and 1 .

\section{RESEARCH METHOD}

The object of research is heart defects (abnormal) and normal. Literature studies are carried out with various approaches where the knowledge of an expert (expert), especially in the field of the heart, is used as a source of knowledge, where the source of basic knowledge is based on the results of a cardiologist's examination and is supported by the results of the examination of the electrocardiogram medical record, where the result of the electrocardiogram is a heart rhythm record. The stages in the development to diagnose heart defects with the certainty factor approach with multiple rules. This research carried out several stages, namely by conducting a literature study, data collection from electrocardiogram medical record data, and initial classification of electrocardiogram medical record data. Data and information from an expert (heart specialist) obtained as material for knowledge, where the data includes the value of the interval from the results of the electrocardiogram medical record and the type of heart disorder (abnormal) and normal. Information also includes the $\mathrm{CF}$ value for each symptom based on the level of confidence in the knowledge acquisition process.

\section{RESULTS AND DISCUSSION}

The representation of knowledge in the form of rules results in conclusions in the form of heart defects (abnormal) and normal. Based on the results of knowledge acquisition, the results of the decision tree are assisted by rapidminer software. Application developed by a system that is able to replace a doctor for the identification process of heart defects based on an expert system. Expert system developed with a certainty factor approach with multiple rules. The system designed is very user friendly and interactive, where users don't need a yes or no answer. On the consultation page, the symptoms that are felt in certain parts appear on the system, and on the user consultation page provide $\mathrm{CF}$ values according to confidence, then the $\mathrm{CF}$ value of this $\mathrm{CF}$ value is calculated with the $\mathrm{CF}$ value in the knowledgebase. Following are the stages of the process expert system for heart disease based on electrocardiogram data using certainty factor with multiple rule as shown in Figure 3:

- $\quad$ Select the symptoms of heart failure

- $\quad$ Calculate the CF Rule

- $\quad$ Calculate the CF value of each rule base using combined CF

A knowledge base built in the early stages of research for a system for diagnosing abnormal and normal hearts. Table 1 show the type of heart disease. This information is obtained as a result of knowledge acquisition. Table 1 shows the types of heart defects (abnormal) and normal heart. 


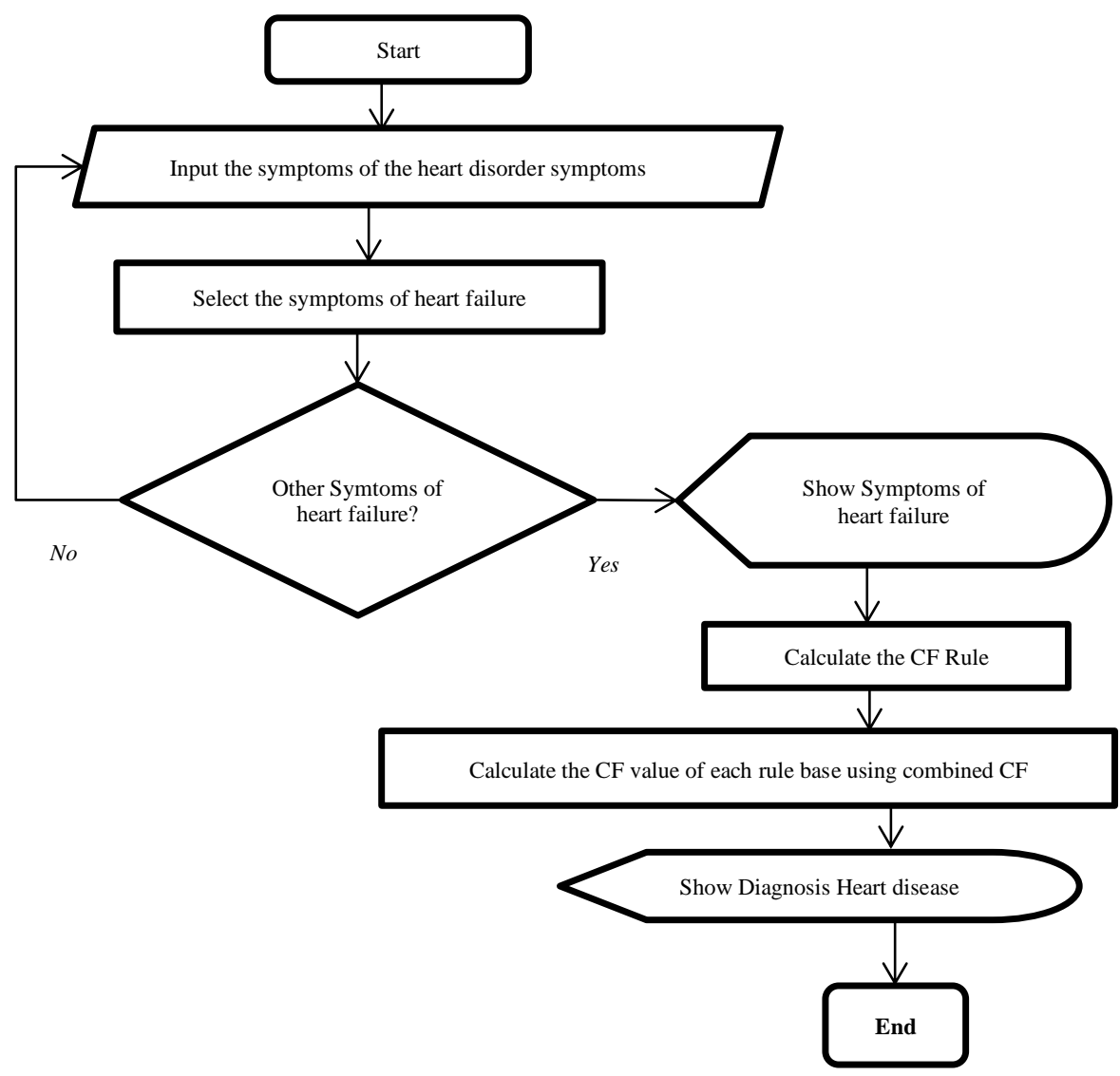

Figure 3. Flowchart expert system consulting process

Table 1. Type of heart disease

\begin{tabular}{cc}
\hline Code & Type of disease \\
\hline P01 & Heart defects (abnormal) \\
P02 & Normal Heart \\
\hline
\end{tabular}

Confidence level values with $\mathrm{CF}$ values 0 to 1 , the more confident the user is with the symptoms experienced, the higher the percentage result value obtained. In selecting user symptoms, it can be done repeatedly according to the symptoms experienced, if the user feels confident about the symptoms experienced, it is necessary to search through the inference process for the selected CF symptoms with a confidence level value with the $\mathrm{CF}$ value. For example, user consultation is:

$$
\begin{aligned}
& \mathrm{R} 1: \mathrm{IF} \text { HR } \leq 104.5 \text { AND SV } 1>-0,526 \text { AND QRS }>84.5 \text { AND } \mathrm{QT} \leq 465.5 \text { AND P-R } \leq 167.5 \\
& \text { AND QTC }>436 \text { AND SV } 1 \leq 0,595 \text { THEN ABNORMAL }
\end{aligned}
$$

The initial rule which has 7 premises is broken down into a rule that has a single premise into:

R1.1 : IF HR $\leq 104.5$ (CF user $=0,6)$ THEN ABNORMAL (CF Expert $=0,8)$

R1.2 : IF SV1 > -0,526 (CF user $=0,6)$ THEN ABNORMAL (CF Expert $=0,8)$

R1.3 : IF QRS > 84.5 (CF user $=0,6)$ THEN ABNORMAL (CF Expert $=0,8)$

R1.4 :I F QT $\leq 465.5$ (CF user $=0,6$ ) THEN ABNORMAL (CF Expert $=0,8$ )

R1.5 : IF P-R $\leq 167.5$ (CF user $=0,6)$ THEN ABNORMAL (CF Expert $=0,8)$

R1.6 : IF QTC $>436$ (CF user $=0,6)$ THEN ABNORMAL (CF Expert $=0,8$ )

R1.7 : IF SV1 $\leq 0,595$ (CF user $=0,6)$ THEN ABNORMAL (CF Expert $=0,8)$

Then the CF value is calculated by multiplying the new rules

CF Expert with $\mathrm{CF}$ user becomes:

$\mathrm{CF}$ R $1.1=0,8 * 0,6=0,48$ 
CF R $1.2=0,8 * 0,6=0,48$

CF R $1.3=0,8 * 0,6=0,48$

CF R $1.4=0,8 * 0,6=0,48$

CF R $1.5=0,8 * 0,6=0,48$

CF R1.6 $=0,8 * 0,6=0,48$

CF R $1.7=0,8 * 0,6=0,48$

Combine CF R1.1 with CF R1.2 with the following formula

CF comb (CF R1.1, CF R1.2) = CF R1.1 + CF R1.2 $(1-$ CF R1.1) =0,48 + 0,48 $(1-0,48)=0,73$

$\mathrm{CF}$ comb (CFold , CF R1.3) = CF old + CF R1.3 $(1-\mathrm{CF}$ old $)=0,73+0,48(1-0,73)=0,86$

CF comb (CFold ,CF R1.4) = CF old + CF R1.4 $(1-$ CF old $)=0,86+0,48(1-0,86)=0,93$

CF comb (CFold , CF R1.5) $=$ CF old + CF R1.5 $(1-$ CF old $)=0,93+0,48(1-0,93)=0,96$

CF comb (CFold ,CF R1.6) $=$ CF old + CF R1.6 $(1-$ CF old $)=0,96+0,48(1-0,96)=0,98$

CF comb (CFold , CF R1.7) $=$ CF old + CF R1.7 $(1-$ CF old $)=0,98+0,48(1-0,98)=0,99$

Confidence percentage $=\mathrm{CF}$ Combine $* 100 \%$

$=99 \%$

System testing is carried out from the results of the system validity with experts, so that the system test results produce a certainty factor value for an abnormal heart of 0.99 and an accuracy of $99 \%$.

R2: IF HR $\leq 104.5$ AND SV1 $>-0,526$ AND QRS $>$ 84.5 AND QT $\leq 465.5$ AND P-R $\leq 167.5$ AND QTC $\leq$ 436 THEN NORMAL

The initial rule which has 6 premises is broken down into a rule that has a single premise into:

R 2.1: IF HR $\leq 104.5$ (CF user $=0,8)$ THEN NORMAL (CF Expert =0,6)

R 2.2: IF SV1 > -0,526 (CF user $=0,6)$ THEN NORMAL (CF Expert $=0,6)$

R 2.3: IF QRS > 84.5 (CF user $=0,6)$ THEN NORMAL (CF Expert $=0,6$ )

R 2.4: IF QT $\leq 465.5$ (CF user $=0,6)$ THEN NORMAL (CF Expert $=0,6$ )

R 2.5: IF P-R $\leq 167.5$ (CF user $=0,6)$ THEN NORMAL (CF Expert $=0,6)$

$\mathrm{R}$ 2.6: IF QTC $\leq 436$ (CF user $=0,6)$ THEN NORMAL (CF Expert $=0,8$ )

Then the $\mathrm{CF}$ value is calculated by multiplying the new rules

CF Expert with CF user Becomes:

CF R2. $1=0,6 * 0,8=0,48$

CF R2.2 $=0,6 * 0,6=0,36$

CF R2.3 $=0,6 * 0,6=0,36$

$\mathrm{CF} \mathrm{R} 2.4=0,6 * 0,6=0,36$

CF R2.5 $=0,6 * 0,6=0,36$

CF R2.6 $=0,8 * 0,6=0,48$

Combine CF R2.1 with CF R2.2 with the following formula:

CF comb (CF R2.1,CF R2.2) = CF R2.1 + CF R2.2 $(1-$ CF2.1) $=0,48+0,36(1-0,48)=0,66$

CF comb (CFold , CF R2.3) = CF old + CF R2.3 $(1-$ CF old $)=0,66+0,36(1-0,66)=0,78$

CF comb (CFold , CF R2.4) = CF old + CF R2.4 $(1-$ CF old $)=0,78+0,36(1-0,76)=0,86$

CF comb (CFold , CF R2.5) = CF old + CF R2.5 $(1-$ CF old $)=0,86+0,36(1-0,86)=0,91$

CF comb (CFold , CF R2.6) $=$ CF old + CF R2.6 $(1-$ CF old $)=0,91+0,48(1-0,91)=0,95$

Confidence percentage $=\mathrm{CF}$ Combine $* 100 \%$

$=95 \%$

System testing is carried out from the results of the system validity with experts, so that the system test results produce a certainty factor value for a normal heart of 0.95 and an accuracy level of $95 \%$. Table 2 shows the results of the search for an expert system with a combination value of certainty factor (CF), system testing is carried out from the results of system validity with experts, resulting in the certainty factor (CF) value and the value of normal and abnormal heart accuracy levels is: this research is implemented in cases of cardiac disorders, but can be implemented in other cases such as diagnoses of other diseases. The research results obtained are in the form of a confidence level value that will result in determining a good final result, where the system in its application is not only to provide a single diagnosis result, but it can produce a 
diagnosis with symptoms that are felt in accordance with the calculation of the combination of rules (multiple rules).

Table 2. CF combination value of expert systems search results

\begin{tabular}{ccc}
\hline Heart Disease & CF value & Accuracy $(\%)$ \\
\hline Normal & 0,95 & $95 \%$ \\
Abnormal & 0,99 & $99 \%$ \\
\hline
\end{tabular}

\section{CONCLUSION}

This study aims to develop a system or software that can replace a doctor for the process of identifying heart defects based on an expert system. Expert systems developed with a certainty factor approach with multiple rules, where the process of executing rules, several rules can produce a hypothesis. System testing is carried out from the results of the system validity with experts, so that the system test results produce the certainty factor $(\mathrm{CF})$ value for a normal heart of 0.95 and an accuracy level of $95 \%$, while the certainty factor (CF) value for an abnormal heart is 0.99 and produces an accuracy level value $99 \%$.

\section{REFERENCES}

[1] Triayudi A, Fitri I, "Comparison of Parameter-Free Agglomerative Hierarchical Clustering Methods," Icic Express Letters, vol. 12, no.10, pp. 973-980, 2018, doi: 10.24507/icicel.12.10.973.

[2] Triayudi, A. and Fitri, I, "Alg Clustering To Analyze The Behavioural Patterns Of Online Learning Students," Journal of Theoretical \& Applied Information Technology, vol 96, no.16, pp.5327-5337, 2018, ISSN: 1992-8645.

[3] Triayudi, A. and Fitri, I, "A new a gglomerative hierarchical clustering to model student activity in online learning," Telkomnika, vol. 17, no.3, pp.1226-1235, 2019, doi: 10.12928/telkomnika.v17i3.9425.

[4] Niskanen, V.A, "Randomized Statistical System for Expert Diagnosis of Vehicle Damage in Wuling Confero Cars Using the Certainty Factor Method," Jsil Jurnal Sistem Informasi, vol 7, no.1 march 2020 63-64, 2020, doi.org/10.30656/jsii.v7i1.2107.

[5] Munandar Tb Ai, Suherman, Sumiati, "The Use of Certainty Factor With Multiple Rules for Diagnosing Internal Disease," International Journal of Application or Innovation in Engineering \& Management (IJAIEM), Volume 1,Issue 1, September 2012, ISSN 2319-4847.

[6] Sugianto, Sumiati, "Expert System for Diagnosing Cancer in Children using the Certainty Factor Method," Prosisko Jurnal Pengembangan Riset dan Observasi Sistem Komputer, vol 3, no.1, 2016

[7] Kristyanto K, Sumiati, "Expert System for Diagnosing Vehicle Damage on Wuling Confero S Cars Using the Certainty Factor Method,” Jurnal Sistem Informasi (JSII), vol. 7, no.1, doi 10.30656/jsii.v7i1,2017.

[8] Setiabudi,W,U., Sugiharti, E., Arini, F, Y, "Expert System Diagnosis Dental Disease Using Certainty Factor Method," Science Journal of Informatics, vol 4, no,1, pp. 43-50, 2017, doi: 10.1088/1742-6596/1230/1/012063.

[9] Muslim, Much Aziz. et al., "Expert System Diagnosis Chronic Kidney Disease Based on Mamdani Fuzzy Inference System," Journal of Theoretical and Applied Information Technology, vol. 78, no. 1, pp. 70-75, 2015, doi: 10.15294/sji.v4i1.8463.

[10] Aji, A.H., Furqon, M.T., \& Widodo, A.W, "Expert System for Diagnosing Diseases of Pregnant Women Using the Certainty Factor (CF) Method," Jurnal Pengembangan Teknologi Informasi dan Ilmu Komputer, vol. 10, no. 2, pp. 2127-2134, 2018, doi:10.31849/digitalzone.v10i2.2781.

[11] Gunawan, E.P., \& Wardoyo, R, "An Expert System Using Certainty Factor for Determining Insomnia Acupoint," Indonesian Journal Computing Cybernetics System (IJCCS), vol. 12, no.2, pp. 119, 2018, doi: 10.22146/ijccs.26328.

[12] Barbeda J. G. A., "Expert Systems Applied to Plant Disease Diagnosis: Survey and Critical View," IEEE Latin America Transactions, vol. 14, no. 4, April 2016, doi: 10.1109/TLA.2016.7483534.

[13] Kirana, C., Pradana,H,A., Sulaiman, R., "Intestine Disease Diagnosis System Using Certainty Factor Method," Scientific Journal of Informatics, vol 6, no. 1, pp. 82-94, 2019, DOI: 10.15294/sji.v6i1.

[14] Astuti, I., \& Sutarno, H, "The expert system of children's digestive tract diseases diagnostic using combination of forward chaining and certainty factor methods," 3rd International Conference on Science in Information Technology (ICSITech), pp. 608-612, IEEE, 2017, doi: 10.1109/ICSITech.2017.8257185.

[15] Riza, L. S., Pradini, M., \& Rahman, E. F, “An expert system for diagnosis of sleep disorder using fuzzy rule-based classification systems," In IOP Conference Series, Materials Science and Engineering, vol. 185, no. 1, IOP Publishing, 2017, DOI: 10.1088/1757-899X/185/1/012011.

[16] Terri G. Monk, M.D., et al., "Predictors of Cognitive Dysfunction after Major Noncardiac Surgery," Anesthesiolog, vol. 108, pp. 18-30, 2008, https://doi.org/10.1097/01.anes.0000296071.19434.1e.

[17] Bélaïd Bouhemad, M.D., et al., "Echocardiographic Doppler Estimation of Pulmonary Artery Pressure in Critically Ill Patients with Severe Hypoxemia," Anesthesiology, vol. 108, pp. 55-62., January 2008, doi:10.1097/01.anes.0000296067.02462.34.

[18] Catherine C. Price., et al., "Type and Severity of Cognitive Decline in Older Adults after Noncardiac Surgery," Anesthesiology, vol. 108, pp. 8-17, 2008, doi:10.1097/01.anes.0000296072.02527.18. 
[19] Santosh I. Patel, M. D., F. R. C. A., Michael J. Souter, M. B., Ch. B., F. R. C. A., David S. Warner, M. D., Mark A. Warner, M. D., "Equipment-related Electrocardiographic Artifacts: Causes, Characteristics, Consequences, and Correction," vol. 108, pp. 138-148, 2018, doi:10.1097/01.anes.0000296537.62905.25.

[20] Aziz A, and Rehman A U, "Detection of Cardiac Disease using Data Mining Classification Techniques," International Journal of Advanced Computer Science and Applications(IJACSA), vol.8, no.7, pp. 256-259, 2017

[21] Raihan M., Mondal S., More A., Boni P. K., and Sagor M. O. F., "Smartphone Based Heart Attack Risk Prediction System with Statistical Analysis and Data Mining Approaches," Advances in Science Technology and Engineering Systems Journal, vol. 2, no 3, pp. 1815-1822, 2017.

[22] Munandar Tb Ai., Sumiati., Rosalina, V., "Cardiovascular Disease Classification Based on Echocardiography and Electrocardiogram Data Using The Decision Tree Classification Approach," Journal Of Theorical and Applied Information Technology, ISSN: 19992-8645, pp. 50-59, 2020.

[23] Munandar Tb Ai., Sumiati., Rosalina, V., "Pattern of symptom correlation on type of heart disease using approach of pearson correlation coefficient," IOP Conf. Series: Materials Science and Engineering 830, 022086 IOP Publishing, doi:10.1088/1757-899X/830/2/022086, 2020.

[24] Sumiati., Kusprianto., Hasballah., Sigit, H., T., "Design Development and Implementation Of Android based Electrocardiogram Reader," International Journal Of Advanced Research in Compouter Science, vol. 9, no. 5, doi.10.26483/ijarcs.v915.6285, 2018.

[25] Sumiati et al., "Telemedicine Systems for Electrokardiogram to Improve Public Health Services," International Journal of Computer Application, (0975-8887), vol. 176, no. 6, 2017.

[26] Sumiati, Sigit,H,T., "Design of Android Application for Telemedicine System to Improve Public Health," Services.MATEC Web of Conferences 218, 03005, 2018, doi:10.1051/matecconf/201821803005 ICIEE.

[27] Steinberg, et al, "2017 ISHNE-HRS expert consensus statement on ambulatory ECG and external cardiac monitoring/telemetry," Heart Rhythm, doi: http://dx.doi.org/10.1016/j.hrthm, 2017.

[28] Magri, et al., "QT spatial dispersion and sudden cardiac death in hypertrophic Cardiomyopathy," Journal of Cardiology Time for reappraisal, 2017, doi:doi.org/10.1016/j.jjcc.2017.01.006 0914-5087/_2017 Japanese College of Cardiology, Published by Elsevier Ltd. All rights reserved.

[29] Mathews, et al., "A novel application of deep learning for single-lead ECG classification," doi:doi.org/10.1016/j.compbiomed.2018.05.013, Published by Elsevier Ltd, 2018.

[30] Abdu, A. M., Mokhjii, M. M. M., Sheikh, U. U. U., "Machine Learning for Plant Disease Detection," An Investigative Comparison Between Support Vector Machine and Deep Learning, IAES International Journal Of Artificial Intellegent (IJ-AI), vol. 9, no. 4, 2020, doi: http://doi.org/10.11591/ijai.v9.i4.pp\%25p.

[31] Ramachandran, A., Ramesh, A., Sukhlecha, A., Pandey, A., Karuppiah, A., "Machine learning algorithms for fall detection using kinematic and heart rate parameters-a comprehensive analysis," IAES International Journal Of Artificial Intellegent (IJ-AI), vol 9, no. 4, 2020, doi: http://doi.org/10.11591/ijai.v9.i4.pp772-780.

[32] S. Zhao, W. Li, W. Niu, R. Gravina, G. Fortino, "Recognition of human fall events based on single tri-axial gyroscope," IEEE 15th International Conference on Networking, Sensing and Control (ICNSC), pp. 1-6, doi: 10.1109/ICNSC.2018.8361365, 2018.

[33] A. Ramachandran, K. R. Anupama, "A Survey on Recent Advances in Wearable Fall Detection Systems," BioMed Research International, doi: 10.1155/2020/2167160, 2020.

[34] Priyan Malarvizhi Kumar, Usha Devi Gandhi, "A novel three-tier Internet of Things architecture with machine learning algorithm for early detection of heart diseases," Computers and Electrical Engineering, vol. 65, pp. 222235, 2018, http:// dx.doi.org/10.1016/j.compeleceng,2017.09.001.

[35] Patel, et al., "Heart Disease Prediction Usinh Machine Learning and Data Mining Technique," Journal IJCSC, vol. 7, no. 1, pp. 129-137, doi: 10.090592/IJCSC.2016.018, 2015.

[36] Gonzalo N’apoles, Maikel Leon Espinosa, Isel Grau and Koen Vanhoof, "FCM Expert: Software Tool for Scenario Analysis and Pattern Classification Based on Fuzzy Cognitive Maps," International Journal on Artificial Intelligence Tools, vol. 27, no. 7, pp. 25, World Scientific Publishing Company, doi: 10.1142/S0218213018600102, 2018.

[37] Gerardo,F, Gonzalo N'apoles , Rafael "A Review on Methods and Software for Fuzzy Cognitive Maps," Artificial Intelligence Review, 2017, doi: 10.1007/s10462-017-9575-1.

[38] Feshki, et al., "Improving the Heart Disease Diagnosis by Evolutionary Algorithm of PSO and Feed Forward Neural Network," 2016, doi: 10.1109/RIOS.2016.7529489.

[39] Faziludeen, et al., "ECG Beat Classification using Evidential K-Nearest Neighbour," Twelfth International MultiConference on Information Processing, 2016, doi: 10.1016/j.procs.2016.06.106.

[40] Hassan and Haque, "An expert system for automated identification of obstructive sleep apneafrom single-lead ECG using random under sampling boosting," Published by Elsevier B.V, 2017, doi.org/10.1016/j.neucom.2016.12.062.

[41] J. M., et al., "The value of the 12-lead ECG for evaluation and optimization of cardiac resynchronization therapy in daily clinical practice," Journal of Electrocardiology 47 Elsevier Inc., 2014, doi.org/10.1016/j.jelectrocard.

[42] Lindow M. D., et al., "A patient with non-ST-segment elevation acute coronary syndrome: Is it possible to predict the culprit coronary artery," doi: 10.1016/j.jelectrocard, 2016.

[43] Ammar Al-Dallal, et al., "Prediction of Non-Communicable Diseases Using Class Comparison Data Mining," Advances in Science, Technology and Engineering Systems Journal, vol. 4, no. 5, 193-206, 2019, https://dx.doi.org/10.25046/aj040525. 